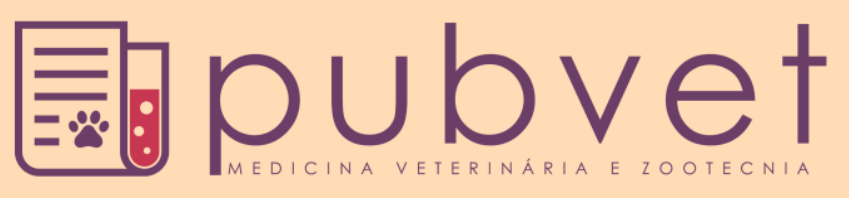

HTTP://DX.DOI.ORG/10.22256/PUBVET.V11N10.1008-1014

\title{
Intoxicação de bovinos por ácido cianogênico e nitrito/nitrato em pastagens de manejo intensivo
}

\author{
Priscila Andriely Bosak ${ }^{1 *}$, Sebastião Brasil Campos Lustosa ${ }^{2}$, Jean Marcel Ferrão \\ Sandrini $^{3}$
}

${ }^{1}$ Mestranda do Programa de Pós-graduação em Ciências Veterinárias pela Universidade Estadual do Centro Oeste, Departamento de Veterinária. Guarapuava-PR, Brasil.E-mail: priscila.bosak@hotmail.com

${ }^{2}$ Professor da Universidade Estadual do Centro-Oeste, Departamento de Agronomia. Guarapuava - PR, Brasil. E-mail: slustosa@unicentro.br

${ }^{3}$ Médico Veterinário, autônomo, Chopinzinho-PR, Brasil.E-mail: jeansandrini@gmail.com

*Autor para correspondência

RESUMO. O aumento da produção das plantas forrageiras, visando ampliação na escala de produção animal e maior produtividade e utilização da terra ocorrem pelo manejo intensivo de pastagens. Essa alternativa possibilita a produção de grande quantidade de forragem por área, e esse aumento de produção geralmente é obtido pela adubação nitrogenada. O nitrogênio é considerado elemento essencial para as plantas, está presente na composição de inúmeras enzimas e compostos constituintes da estrutura vegetal, sendo que sua deficiência consiste, muitas vezes, no principal fator limitante do crescimento vegetal. Porém, sob certas condições do meio, tais como disponibilidade de água, temperatura e acidez do solo, pode acontecer acúmulo de nitrato nas plantas, elemento tóxico quando consumido em grandes quantidades e sem adaptação na dieta dos animais. O ácido cianídrico é um dos venenos de ação mais rápida que se conhece para mamíferos, e o uso de nitrogênio propicia seu acúmulo nas plantas, pois quanto mais nova e de crescimento rápido for a planta, maior será o seu teor em glicosídeos cianogênicos, precursores do ácido cianídrico. Ambas as intoxicações são pouco diagnosticadas, pois causam morte súbita, muitas vezes sem observação de sinais clínicos. O presente trabalho fez uma revisão sobre causas, sinais clínicos e forma de diagnóstico destas intoxicações, relacionada ao nitrogênio presente nas pastagens manejadas de forma intensiva.

Palavras chave: ácido cianídrico, acúmulo, intoxicação, plantas forrageiras

\section{Bovine intoxication by cyanogenic acid and nitrite/nitrate in pastures of intense management}

ABSTRACT. The increase of fodder plants production, aiming growth of animal production scale and higher productivity and use of the land, occurs through intensive management of pastures. This alternative allows the production of a great quantity of forage per area, and this production gain is usually obtained by nitrogenous adubation. Nitrogen is considered an essential element for plants, it is present in the composition of various enzymes and constituents compounds of vegetal structure, being that its deficiency consists, often, in the principal limiting factor of vegetal growth. However, under certain environment conditions, such as water availability, temperature and soil acidity, it may happen accumulation of nitrate in the plants, toxic element when consumed in great quantities and without adaptation in animals' diets. The cyanogenic acid is one of the poisons of fastest action known for mammals, and the use of nitrogen propitiates its accumulation in plants, because the younger the plant and the faster growth rate, the higher its cyanogenic glycosides content, precursors of hydrocyanic acid. Both intoxications are 
rarely diagnosed, because they cause sudden death, often without observation of clinical signals. The present work does a review upon causes, clinical signal and way of diagnosis of these intoxications, related to nitrogen present in pastures managed in an intensive way.

Keywords: hydrocyanic acid, accumulation, intoxication, fodder plants

\section{Intoxicación de bovinos por ácido cianogenico y nitrito/nitrato en pastos de manejo intensivo}

RESUMEN. La intensificación de la producción de plantas forrajeras, buscando el aumento en la escala de producción animal y mejor productividad y uso del suelo, se produce por manejo intensivo de pastos. Esta alternativa permite la producción de gran cantidad de forrajes por área, y esa mayor producción es obtenida por la fertilización nitrogenada. Como el nitrógeno es considerado elemento esencial para las plantas, estando presente en la composición de varias enzimas y compuestos de la estructura vegetal, muchas veces su deficiencia consiste en el principal factor limitante del crecimiento vegetal. Sin embargo, cuando hay condiciones favorables como disponibilidad de agua, temperatura y acidez del suelo, puede ocurrir la acumulación de nitrato en las plantas, un elemento tóxico cuando es consumido en gran cantidad por los animales, sin que estos pasen por adaptación nutricional. El ácido cianhídrico es uno de los veneno de más rápida acción para los mamíferos, y el uso de nitrógeno puede causar su acumulación en las plantas. Cuanto más joven y de crecimiento rápido sea la planta, mayor será su contenido de glucósidos cianogénicos. Ambas intoxicaciones son poco diagnosticadas porque causan muerte súbita, sin presentar síntomas clínicos en muchos casos. El objetivo de este trabajo fue hacer una revisión acerca de causas, síntomas clínicos e diagnósticos de estas intoxicaciones, relacionadas con el nitrógeno presente en los pastos manejados de forma intensiva.

Palabras clave: ácido cianhídrico, acumulación, intoxicación, plantas forrajeras

\section{Introdução}

Atualmente, existe um grande interesse relacionado com a necessidade de intensificação da atividade pecuária, com foco principal no aumento da produtividade dos fatores de produção, especialmente da terra, visando consequente aumento na escala de produção. Este cenário traz o manejo intensivo de pastagens como uma das melhores alternativas de uso eficiente da terra, pois possibilita a produção de grande quantidade de forragem por área, aliada a bom valor nutricional desta forragem (Pereira et al., 2012, Pilau et al., 2005, Frizzo et al., 2003).

$\mathrm{O}$ aumento da produção das plantas forrageiras tropicais é modulado pela adubação nitrogenada (Castagnara et al., 2011, Teixeira et al., 2011). Todavia, essa prática pode causar acúmulo de nitratos e nitritos em altas concentrações em alguns alimentos, particularmente em gramíneas forrageiras no início do estágio vegetativo, fertilizados com grandes quantidades de nitrogênio (Jönck et al., 2013). A concentração dos glicosídeos cianogênicos, precursores do ácido cianídrico, também pode ser influenciada pela adubação nitrogenada, pois quanto mais nova e de crescimento rápido for a planta, maior será o seu teor em glicosídeos cianogênicos (Amorim et al., 2006).

O presente trabalho tem como objetivo fazer uma revisão sobre a etiologia, sinais clínicos, diagnóstico e tratamento de intoxicações por nitratos e ácido cianogênico em bovinos, relacionados a pastagens sob manejo intensivo. A palavra introdução deve estar em negrito e sem recuo.

\section{Intoxicação por nitrito/nitrato}

$\mathrm{O}$ nitrogênio $(\mathrm{N})$ é o elemento químico com maior concentração na atmosfera; porém os animais e as plantas não conseguem absorvê-lo diretamente do ar (Bredemeier and Mundstock, 2000). Ao contrário do carbono e do oxigênio, o nitrogênio é muito pouco reativo do ponto de vista químico, e apenas certas bactérias de vida livre, simbiontes e cianobactérias possuem a capacidade altamente especializada de assimilar o nitrogênio da atmosfera e convertê-lo numa forma que pode ser usada pelas células. Para ser absorvido o gás nitrogênio $\left(\mathrm{N}_{2}\right)$ deve ser fixado ao solo. Isso ocorre na natureza pelas descargas elétricas, fixação 
biológica pelas bactérias de vida livre ou bactérias simbióticas como as do gênero Rhizobiun ou pelo processo industrial na produção da ureia, o adubo mais utilizado mundialmente (Bredemeier and Mundstock, 2000).

No ciclo do nitrogênio, bactérias denominadas fixadoras de nitrogênio conseguem utilizar $\mathrm{N}_{2}$ atmosférico para produzir íons nitrato que são liberados no ambiente (solo e água) e absorvidos pelas plantas. Os animais absorvem nitrogênio via nível trófico. O nitrogênio retorna ao ambiente em forma de amônia $\left(\mathrm{NH}_{3}\right)$ pela decomposição animal e vegetal. Bactérias nitrificantes convertem amônia em nitrito $\left(\mathrm{NO}_{2}\right)$, e nitrito em nitrato $\left(\mathrm{NO}_{3}\right)$, enriquecendo o meio (Bredemeier and Mundstock, 2000 .

O nitrogênio é considerado elemento essencial para as plantas, ligado diretamente ao teor de proteína e ao crescimento, pois está presente na composição das mais importantes biomoléculas, tais como ATP (adenosina trifosfato), clorofila, proteínas e inúmeras enzimas e compostos que participam ativamente na síntese dos compostos orgânicos constituintes da estrutura vegetal. Portanto, é responsável por características ligadas ao porte da planta, tais como o tamanho das folhas, tamanho do colmo, formação e desenvolvimento dos perfilhos (Bredemeier and Mundstock, 2000, Costa et al., 2008b, Teixeira et al., 2011). O local primário para conversão do nitrato nesses produtos são as folhas verdes em crescimento (Jönck et al., 2013). A deficiência de nitrogênio utilizável constitui, muitas vezes, o principal fator limitante do crescimento vegetal, influenciando o crescimento da planta mais do que qualquer outro nutriente (Bredemeier and Mundstock, 2000, Costa et al., 2008b).

A magnitude de resposta da planta a esse insumo varia com a espécie forrageira, a dose, a fonte, o modo de aplicação do fertilizante, a forma de utilização de pastagem (corte ou pastejo), tipo do solo e com as condições de clima (temperatura e umidade), antes, durante e depois da aplicação da adubação (Costa et al., 2008a). Sua deficiência é caracterizada pelo amarelecimento das folhas (clorose), iniciando-se nas folhas mais velhas, reduzindo a taxa fotossintética e proporcionando menor crescimento das plantas (Costa et al., 2008a, Costa et al., 2008b). A intensificação no uso da forragem produzida torna mais importante a reposição de nutrientes ao sistema para garantir as condições de rápido restabelecimento da planta forrageira, reconhecendo que o grande benefício do nitrogênio está em acelerar o crescimento e a recuperação da planta após o pastejo (Paciullo et al., 2011, Paciullo et al., 1998). Existem várias fontes de nitrogênio que podem ser usadas em pastagens, contudo, as mais comuns são a ureia (44 a $46 \%$ N), o sulfato de amônio (20 a 21\% N) e o nitrato de amônio (32 a 33\% N) (Costa et al., 2008b, Valadares Filho et al., 2016). No caso de sistemas de produção animal em pastejo, o $\mathrm{N}$ da excreta do animal também contribui para nutrição nitrogenada da planta forrageira, na área de influência da excreta (Costa et al., 2008a, Costa et al., 2008b). O uso excessivo de matéria orgânica contribui para o acúmulo de nitrato em algumas plantas (Jönck et al., 2013).

A eficiência da adubação nitrogenada depende da temperatura, da luminosidade e da disponibilidade de água. A quase totalidade do nitrogênio é absorvida por fluxo de massa, ou seja, a água absorvida pelas raízes carrega o nutriente (Bredemeier and Mundstock, 2000). Assim, para serem absorvidos pelas raízes, os nutrientes precisam estar disponíveis em solução, junto ou próximo às raízes (Costa et al., 2006). Durante a seca há baixa disponibilidade de água no solo comprometendo a absorção de nutrientes pelas plantas. Após a chuva o crescimento das plantas é acelerado e estas incorporam grande quantidade de nitrato, ocorrendo maior acúmulo deste elemento nas plantas (Jönck et al., 2013).

Outras condições que ocasionam acúmulo de nitrato nas plantas são: altos níveis de nitrato no solo e maior captação pelas plantas devido a fertilização com adubos nitrogenados ou matéria orgânica de origem animal; fatores ambientais como sombra e nebulosidade; e características do solo, tais como temperatura, acidez e deficiências minerais (Medeiros et al., 2014). O nitrogênio pode ser absorvido pelas plantas principalmente nas formas de amônio $\left(\mathrm{NH}_{4}\right)$ e nitrato $\left(\mathrm{NO}_{3}\right)$. A absorção de nitrato é maior em $\mathrm{pH}$ ácido, enquanto a absorção de amônia é maior em $\mathrm{pH}$ próximo de neutro, decrescendo com o aumento da acidez. Em condições normais de solo, a forma de nitrato é frequentemente dominante por ser a forma iônica de maior liberdade para movimentação em direção às raízes das plantas (Costa et al., 2008a).

Essas condições que propiciam acúmulo fazem com que os nitratos representem mais de $30 \%$ do nitrogênio das plantas, sendo que plantas que possuem mais de $3 \%$ de nitrogênio na matéria seca já são capazes de produzir quadros de intoxicação. Algumas plantas também são conhecidas por 
conter elevados níveis de nitrato, como o sorgo (Sorghum sp), aveia (Avena sativa), azévem (Lolium spp), trigo (Triticum vulgare), milho (Zea mays), e capim elefante (Pennisetum purpureum) (Jönck et al., 2013). A alta taxa de adubação nitrogenada é um fator importante que pode contribuir para o acúmulo de nitrato nas plantas. Plantas jovens que crescem rapidamente geralmente contêm níveis mais altos de nitrato do que as plantas maduras (Jönck et al., 2013).

Em bovinos, quando há presença de substrato (nitrato), as enzimas nitrato redutase são produzidas e fazem a redução do nitrato a nitrito e, posteriormente, de nitrito para amônia. A amônia que não é incorporada nos compostos nitrogenados microbianos é absorvida através do epitélio ruminal e entra na circulação portal, chegando ao fígado, onde é convertida em ureia (Jönck et al., 2013). A necessidade de equivalentes de redução para converter nitrato em nitrito é bem menor que para transformar nitrito em amônia. Desta forma, quando a taxa de nitrato no rúmen é alta ocorre o acúmulo de nitrito. $\mathrm{O}$ metabolismo excessivo de nitrito no rúmen ocorre quando há um consumo elevado e sem adaptação do nitrato na dieta, falta de adaptação dos organismos ruminais ao nitrato e dietas excessivamente ricas em proteínas degradáveis no rúmen (Jönck et al., 2013). O nitrito em elevadas concentrações no rúmen é absorvido pelos capilares ruminais e, quando atinge a corrente sanguínea, afeta as células vermelhas do sangue oxidando a molécula heme da hemoglobina e convertendo a hemoglobina em um tipo de disemoglobina conhecida como metemoglobina (MetHb), que não carreia oxigênio (Jönck et al., 2013).

Os animais podem não apresentar alterações e morrer subitamente. Quando há sinais clínicos, eles surgem em até 14 horas após a ingestão do nitrato e podem ser discretos e surgir de forma súbita. Os principais sinais clínicos observados são sialorreia, ranger dos dentes, cansaço, taquipneia, ataxia, tremores musculares, andar cambaleante, mucosas cianóticas, decúbito, relutância em se movimentar, crise convulsiva e abortos (Radostits et al., 2010).

Medeiros et al. (2014) ao relatarem três surtos de intoxicação por nitrato ocorridos no sertão da Paraíba descrevem que os sinais clínicos caracterizaram-se por dispneia com respiração com o pescoço estendido, ranger de dentes, anorexia, apatia ou hiperexcitabilidade, tremores, contrações abdominais, salivação, corrimento nasal, andar cambaleante, mucosas cianóticas, pelos arrepiados e decúbito. O curso clínico variou de 2 a 9 horas e depois de estar em decúbito a morte ocorria em aproximadamente 30 minutos.

Os bovinos toleram valores de 15 a $40 \%$ de $\mathrm{MetHb}$, sendo que valores acima de $40 \%$ são capazes de ocasionar alteração na coloração das mucosas tornando-as amarronzadas (descritas como cor de chocolate). O sinal clínico evidente de falta de oxigênio aparece principalmente com valores de $50-60 \%$ e o óbito pode ocorrer com níveis de $80 \%$ de metemoglobina. Ao exame clínico observam-se, de forma característica, mucosas cianóticas ou amarronzadas e sangue de mesma coloração (Jönck et al., 2013, Radostits et al., 2010).

O diagnóstico das intoxicações por nitrato realiza-se pelo histórico do rebanho e da alimentação, sinais clínicos, prova da difenilamina e o exame anatomopatológico. $\mathrm{O}$ diagnóstico terapêutico também é válido, podendo ser confirmado pela rápida resposta do animal ao tratamento (Radostits et al., 2010, Jönck et al., 2013). O tratamento terapêutico recomendado é a administração de azul de metileno a $1 \%$. O azul de metileno combina-se com a metemoglobina redutase, que reduz o azul de metileno a leucoazul de metileno, subproduto metabólico que transforma a MetHb em hemoglobina (Jönck et al., 2013). Jönck et al. (2013) relatam que bovinos intoxicados espontânea e experimentalmente, que receberam azul de metileno a $1 \%$, na dose de $4 \mathrm{mg} / \mathrm{kg}$ e $2 \mathrm{mg} / \mathrm{kg}$ de peso vivo por via intravenosa, respectivamente, apresentaram melhora em poucos minutos após a aplicação, levantando-se e mostrando apetite. A prova da difenilamina pode ser realizada para a detecção de nitrito e nitrato em amostras de capim, fluidos corpóreos, soro, urina e fluidos oculares. A técnica consiste na obtenção de três gotas de extrato vegetal ou de fluido corpóreo, que são colocadas sobre uma lâmina de vidro, onde é adicionada uma gota de reagente. A reação é considerada positiva quando em menos de 10 segundos se forma uma coloração azul intensa (Radostits et al., 2010, Jönck et al., 2013).

A necropsia deve ser realizada logo após a morte do animal, já que em um curto intervalo de horas após a morte a metemoglobina volta a ser hemoglobina, fazendo com que desapareça a coloração escura do sangue, da carcaça e da musculatura, dificultando o diagnóstico (Jönck et al., 2013). A carcaça recém-aberta exala um cheiro 
forte de gases nitrosos, e os principais achados macroscópicos descritos são sangue com coloração escura e com baixa coagulação, coloração vermelha intensa dos músculos cardíacos e esqueléticos e os pulmões podem estar congestos e apresentar hemorragias nas serosas e mucosas (Jönck et al., 2013).

\section{Intoxicação por ácido cianogênico}

São consideradas plantas cianogênicas aquelas que contêm como princípio ativo o ácido cianídrico (HCN) um líquido incolor, muito volátil, considerado como uma das substâncias mais tóxicas conhecidas (Amorim et al., 2006, Amorim et al., 2005, Nóbrega Júnior et al., 2006, Câmara et al., 2014). As plantas cianogênicas mais importantes do Brasil são as do gênero Manihot (Euphorbeaceae), conhecidas como mandioca, macaxeira ou aipim (Amorim et al., 2006, Câmara et al., 2014, Galindo, 2015) que apresentam o maior número de relatos de intoxicação cianogênica no país. Os tubérculos são comestíveis e a intoxicação ocorre quando animais famintos invadem culturas, quando as primeiras chuvas são seguidas de uma estiagem de vários dias e os animais ingerem as plantas em brotação ou secas, ou quando são alimentados logo após a colheita, com as folhas frescas e tubérculos sem os devidos cuidados quanto à eliminação do princípio ativo (Amorim et al., 2006, Galindo, 2015).

Os sorgos (Sorghum hapelense, S. sudanense, $S$. vulgare e variedades híbridas) são empregados em algumas regiões do Brasil para a produção de forragem, podendo produzir alta mortalidade por conter elevadas quantidades de glicosídeos cianogênicos quando estão na fase de crescimento ou quando rebrotam rapidamente em condições favoráveis (Amorim et al., 2006, Nóbrega Júnior et al., 2006, Câmara et al., 2014, Galindo, 2015), geralmente quando as plantas têm menos de vinte centímetros de altura ou sete semanas de plantio, ou quando as plantas jovens rebrotam após terem seu crescimento prejudicado, durante períodos de seca ou após geadas (Amorim et al., 2006).

As espécies Manihot spp. e Sorghum spp são cultivadas em todo o Brasil (Galindo, 2015). No sul e sudeste do país, pessegueiro-bravo (Prunus sellowii) e Tifton (Cynodon dactylon) também são espécies envolvidas em intoxicações (Amorim et al., 2006, Juffo et al., 2012). O HCN é um dos venenos de ação mais rápida que se conhece para mamíferos; trata-se de um composto que nas plantas se encontra combinado a outras substâncias, principalmente a açúcares, formando os glicosídeos cianogênicos (Galindo, 2015). Numerosos glicosídeos têm sido isolados; são produtos secundários do metabolismo das plantas e provavelmente fazem parte do sistema de defesa contra herbívoros e insetos (Galindo, 2015, Amorim et al., 2006). A concentração dos glicosídeos cianogênicos é variável nas diferentes espécies de plantas, e numa mesma espécie varia dependendo do clima e outras condições que influenciam o crescimento da planta como adubação nitrogenada e idade da planta, pois quanto mais nova e de crescimento rápido, maior será o seu teor em glicosídeos cianogênicos. O teor de glicosídeos também pode estar mais elevado durante prolongados períodos de seca, seguidos por um curto período chuvoso, quando a brotação é intensa (Amorim et al., 2006). As enzimas Bglicosidases localizam-se na parede celular e os glicosídeos cianogênicos nos vacúolos intracitoplasmáticos. Quando o material vegetal é dilacerado durante a mastigação, a enzima intracelular é liberada e entra em contato com os glicosídeos, que são hidrolisados enzimaticamente na presença de água (Amorim et al., 2006).

A toxidez e a velocidade de ingestão das plantas cianogênicas constituem os fatores mais importantes para a ocorrência da intoxicação, que geralmente ocorrem quando doses tóxicas são ingeridas em curto período de tempo (Amorim et al., 2006, Nóbrega Júnior et al., 2006, Juffo et al., 2012). Segundo Amorim et al. (2006), a dose tóxica de $\mathrm{HCN}$ é de 2 a $4 \mathrm{mg}$ de $\mathrm{HCN}$ por $\mathrm{kg}$ de peso vivo por hora. Após a ingestão de plantas cianogênicas, os glicosídeos cianogênicos liberam $\mathrm{HCN}$, o qual é rapidamente absorvido no trato digestivo e distribuído para os tecidos pela corrente sanguínea. O HCN bloqueia a cadeia respiratória e impede o aproveitamento do oxigênio pelos tecidos. Bovinos intoxicados podem apresentar dispneia, taquicardia, mucosas cianóticas, tremores musculares, sialorreia, ansiedade, falta de coordenação motora, decúbito lateral e convulsões que precedem as mortes. Como a absorção de $\mathrm{HCN}$ é rápida, esses sinais ocorrem pouco tempo após ou já durante a ingestão das plantas (Amorim et al., 2006, Juffo et al., 2012, Câmara et al., 2014, Galindo, 2015). Na necropsia não se encontram lesões características; destaca-se a cor vermelho-brilhante a vermelho escuro do sangue, que demora a coagular, a musculatura apresenta-se escura, e ocorre congestão pulmonar, renal e hepática. As folhas mastigadas das plantas cianogênicas podem ser 
encontradas no rúmen (Amorim et al., 2006, Galindo, 2015).

É possível verificar a presença de glicosídeos cianogênicos nas plantas pelo teste do papel picrossódico (Nóbrega Júnior et al., 2006, Câmara et al., 2014). Para o teste, prepara-se uma solução de 5 gramas de carbonato de sódio e 0,5 gramas de ácido pícrico dissolvidos em $100 \mathrm{~mL}$ de água destilada. Pequenas tiras de papel filtro são embebidas nessa solução e fixadas, ainda úmidas, em um recipiente com amostras da planta recémmacerada, de forma que o papel fique suspenso acima do material, a uma temperatura de 30 a $35^{\circ}$ C (Juffo et al., 2012, Galindo, 2015). O papel, anteriormente de cor amarela, na presença do HCN muda gradualmente para a cor laranja, seguido do vermelho tijolo. $\mathrm{O}$ aparecimento da cor vermelho tijolo intensa, dentro de 5 a 10 minutos é indicativo de quantidades tóxicas de $\mathrm{HCN}$. Reações discretas aparecem após uma ou mais horas, e ausência de reação quando não há mudança na coloração (Amorim et al., 2006, Galindo, 2015). Este teste tem valor apenas relativo quanto às concentrações dos glicosídeos cianogênicos no material vegetal, uma vez que trabalhos demonstraram que amostras de plantas cianogênicas quando murchas e secas não reagiram ou reagiram lentamente ao teste do papel picrossódico, e mesmo assim foram capazes de causar intoxicação cianídrica, devido ao fato de que as bactérias ruminais podem hidrolisar com rapidez os glicosídeos cianogênicos (Amorim et al., 2006).

Embora na maioria das vezes os animais sejam encontrados mortos, dado a rapidez com que ocorre a morte, o tratamento da intoxicação cianídrica é feito com uma solução aquosa de tiossulfato de sódio a $20 \%$ na dosagem de $50 \mathrm{~mL}$ por $100 \mathrm{~kg}$ de peso vivo por via endovenosa (Amorim et al., 2006).

\section{Conclusão}

É importante buscar meios de exercer o manejo correto das pastagens, principalmente no que diz respeito a adubação nitrogenada, evitando adubação em excesso para prevenir o acúmulo de compostos tóxicos nas plantas. Destaca-se também a importância de atentar para condições do meio que favorecem o acúmulo destes compostos - como estiagem seguida de períodos de chuva, por exemplo, além de condições do solo, temperatura e desenvolvimento das plantas.
O manejo animal deve ser feito com adaptação destes às mudanças na dieta, e não permitir que os animais permaneçam muito tempo em jejum antes de conduzi-los ao pasto, visto que a ingestão acelerada de plantas com princípios tóxicos colabora para o desenvolvimento de quadro clínico de intoxicação.

Sinais clínicos, achados necropsia e resposta ao tratamento, quando instituído, são maneiras de diferenciar intoxicação por nitratos e ácido cianogêncio de outras intoxicações ou afecções que acometem os bovinos.

\section{Referências Bibliográficas}

Amorim, S. L., Mdedeiros, R. M. T. \& RietCorrea, F. 2006. Intoxicações por plantas cianogênicas no Brasil. Ciência Animal, 16, 17-26.

Amorim, S. L., Medeiros, R. M. T. \& Riet-Correa, F. 2005. Intoxicação experimental por Manihot glaziovii (Euphorbiaceae) em caprinos. Pesquisa Veterinária Brasileira, 25, 179-187.

Bredemeier, C. \& Mundstock, C. M. 2000. Regulação da absorção e assimilação do nitrogênio nas plantas. Ciência Rural, 30, 365372.

Câmara, A. C. L., Dalcin, L. \& Soto-Blanco, B. 2014. Patogênese, sinais clínicos e epidemiologia das intoxicações por plantas cianogênicas no nordeste brasileiro. Semina: Ciências Agrárias, 35, 1961-1972.

Castagnara, D. D., Zoz, T., Krutzmann, A., Uhlein, A., Mesquita, E. E., Neres, M. A. \& Oliveira, P. S. R. 2011. Produção de forragem, características estruturais e eficiência de utilização do nitrogênio em forrageiras tropicais sob adubação nitrogenada. Semina: Ciências Agrárias, 32, 1637-1648.

Costa, K. A. P., Faquin, V., Oliveira, I. P., Araújo, J. L. \& Rodrigues, R. B. 2008a. Doses e fontes de nitrogênio em pastagem de capim-marandu: II-nutrição nitrogenada da planta. Revista Brasileira de Ciência do Solo, 32, 1601-1607.

Costa, K. A. P., Oliveira, I. P., Faquin, V., Figueiredo, F. C., Rodrigues, C. R. \& Nascimento, P. P. 2008b. Adubação nitrogenada e potássica na concentração de nutrientes do capim-xaraés. Ciência Animal Brasileira, 9, 86-92.

Frizzo, A., Rocha, M. G. D., Restle, J., Freitas, M. R., Biscaíno, G. \& Pilau, A. 2003. Produção de forragem e retorno econômico da pastagem de 
aveia e azevém sob pastejo com bezerras de corte submetidas a níveis de suplementação energética. Revista Brasileira de Zootecnia, 32, 632-642.

Galindo, C. M. 2015. Intoxicação espontânea e experimental por tifton 68 (Cynodon nlemfuensis vanderyst) em bovino. Lages, Santa Catarina.

Jönck, F., Gava, A., Traverso, S. D., Lucioli, J., Furlan, F. H. \& Gueller, E. 2013. Intoxicação espontânea e experimental por nitrato/nitrito em bovinos alimentados com Avena sativa (aveia) e/ou Lolium spp.(azevém). Pesquisa Veterinária Brasileira, 33, 1062-1070.

Juffo, G. D., Pavarini, S. P., Wouters, F., Oliveira, L. G. S., Antoniassi, N. A. B., Cruz, C. E. F. \& Driemeier, D. 2012. Spontaneous poisoning by Sorghum sudanense in dairy cattle in Rio Grande do Sul. Pesquisa Veterinária Brasileira, 32, 217-220.

Medeiros, R. M. T., Riet-Correa, F., Tabosa, I. M., Silva, Z. A., Barbosa, R. C., Marques, A. V. M. S. \& Nogueira, F. R. B. 2014. Intoxicação por nitratos e nitritos em bovinos por ingestão de Echinochloa polystachya (capim-mandante) e Pennisetum purpureum (capim-elefante) no sertão da Paraíba. Pesquisa Veterinária Brasileira, 23, 17-20.

Nóbrega Júnior, J., Riet-Correa, F., Medeiros, R. M. T. \& Dantas, A. F. M. 2006. Intoxicação por Sorhgum halepense (Poaceae) em bovinos no semi-árido. Pesquisa Veterinária Brasileira, 26, 201-204.

Paciullo, D. S. C., Gomide, C. A. M., Castro, C. R. T., Fernandes, P. B., Müller, M. D., Pires, M. F. A., Fernandes, E. M. \& Xavier, D. F. 2011. Características produtivas e nutricionais do pasto em sistema agrossilvipastoril, conforme a distância das árvores. Pesquisa Agropecuária Brasileira, 46, 1176-1183.

Paciullo, D. S. C., Gomide, J. A. \& Ribeiro, K. G. 1998. Adubação nitrogenada do capim- elefante cv. Mott. 1. Rendimento forrageiro e características morfofisiológicas ao atingir 80 e $120 \mathrm{~cm}$ de altura. Revista Brasileira de Zootecnia, 27, 1069-1075.

Pereira, V. V., Fonseca, D. M., Martuscello, J. A., Cecon, P. R., Santos, M. V. \& G., S. B. T. 2012. Biomass accumulation in mombasa guineagrass plants under different levels of nitrogen supply and plant densities. Revista Brasileira de Zootecnia, 41, 1118-1126.

Pilau, A., Rocha, M. G., Restle, J., Freitas, F. K. \& Roso, D. 2005. Produção de forragem e produção animal em pastagem com duas disponibilidades de forragem associadas ou não á suplementação energética. Revista Brasileira de Zootecnia, 34, 1130-1137.

Radostits, O. M., Gay, C. C., Blood, D. C., Hinchcliff, K. W. \& McKenzie, R. A. 2010. Clínica Veterinária: um tratado de doenças dos bovinos, ovinos, suínos, caprinos e eqüinos. Guanabara Koogan, Rio de Janeiro.

Teixeira, F. A., Bonomo, P., Pires, A. J. V., Silva, F., Fries, D. D. \& Hora, D. 2011. Produção anual e qualidade de pastagem de Brachiaria decumbens diferida e estratégias de adubação nitrogenada. Acta Scientiarum. Animal Sciences, 33, 241-248.

Valadares Filho, S. C., Costa e Silva, L. F., Gionbelli, M. P., Rotta, P. P., Marcondes, M. I., Chizzotti, M. L. \& Prados, L. F. 2016. Exigências nutricionais de zebuínos puros $e$ cruzado - BR-Corte. Universidade Federal de Viçosa, Viçosa, Minas Gerais.

Article History:

Received 12 June 2017

Accepted 21 July 2017

Available on line 24 August 2017

License information: This is an open-access article distributed under the terms of the Creative Commons Attribution License 4.0, which permits unrestricted use, distribution, and reproduction in any medium, provided the original work is properly cited. 